\title{
Os caminhos e descaminhos da sociolinguística histórica no Brasil
}

\author{
Maria Helena Menezes de SOUZA(D) \\ Universidade Federal de Alagoas (UFAL) \\ Suziane de Oliveira Porto SILVA (D \\ Universidade Federal de Alagoas (UFAL)
}

○

OPEN ACCESS

EDITADO POR

Raquel Freitag

REVISADO POR

Huda da Silva Santiago

SOBRE OS AUTORES Maria Helena Menezes de Souza Contribuiu com Suziane de Oliveira Porto Silva. Papéis: escrita - rascunho original, análise e edição

Suziane de Oliveira Porto Silva Contribuiu com Maria Helena Menezes de Souza. Papéis: escrita - rascunho original, análise e edição.

DATAS

Recebido: 24/07/2020 Aceito: 08/10/2020 Publicado: 21/10/2020

COMO CITAR Souza, M. H. M.; Silva, S. O. P

(2020). Os caminhos e descaminhos da sociolinguística
RESUMO

A mesa-redonda Sociolinguística Histórica no Brasil: caminhos e desafios tem como proposta discutir sobre os caminhos e descaminhos da Sociolinguística Histórica no Brasil, apontando como questão central como a natureza do corpus utilizado pode influenciar nos resultados obtidos. Dividida em três momentos a mesa tem início com a professora Célia Regina dos Santos Lopes (UFRJ), abordando reflexões acerca da Sociolinguística Histórica, apresentando cartas como fontes documentais. Posteriormente, a professora Rosane de Andrade Berlink (UNESP) continua as discussões apresentando a utilização de peças de teatro para estudos sócio-históricos da língua, sendo a mesa finalizada com a apresentação da professora Huda da Silva Santiago (UEFS) que trata sobre algumas reflexões acerca da identificação da inabilidade na escrita em corpora diacrônicos.

\section{ABSTRACT}

The Historical Sociolinguistics in Brazil: paths and challenges roundtable proposes to discuss the paths and deviations of Historical Sociolinguistics in Brazil, discussing as a central question how the nature of the corpus used can influence the results obtained. Divided into three moments, the table starts with professor Célia Regina dos Santos Lopes (UFRJ), addressing reflections about historical Sociolinguistics, presenting letters as documentary sources. Subsequently, professor Rosane de Andrade Berlink (UNESP) continues the discussions presenting the use of theater plays for socio-historical studies of the language, with the table ending with a presentation by 


\section{REVISTA DA ABRALIN}

professor Huda da Silva Santiago (UEFS) who deals with some reflections on identification of inability in writing in diachronic corpora.

\section{PALAVRAS-CHAVE}

Linguística Histórica. Sociolinguística Histórica. Desafios.

\section{KEYWORDS}

Historical Linguistics. Historical Sociolinguistics. Challenges.

A mesa-redonda Sociolinguística Histórica no Brasil: caminhos e desafios teve por objetivo discutir sobre os caminhos e descaminhos da Sociolinguística Histórica no Brasil. Para tanto, a mesa foi dividida em três momentos, a saber: reflexões acerca da Sociolinguística Histórica, com a apresentação de cartas como fontes documentais, sendo apresentada por Célia Regina dos Santos Lopes, professora titular de língua portuguesa na Faculdade de Letras da Universidade Federal do Rio de Janeiro (UFRJ); no segundo momento, foram apresentadas peças de teatro como proposta para os estudos sócio-históricos da língua, exposto por Rosane de Andrade Berlink, professora assistente doutor da Universidade Estadual Paulista Júlio Mesquita Filho (UNESP); finalizando com reflexões acerca da identificação da inabilidade na escrita em corpora diacrônicos apresentado por Huda da Silva Santiago, professora assistente da Universidade Estadual de Feira de Santana (PPGEL/UEFS).

Dando início às apresentações, Célia Lopes afirma que o objetivo da Sociolinguística Histórica (SH) é estudar uma teoria de mudança linguística mediante a evolução social. Lopes aponta aspectos convergentes e divergentes da Sociolinguística Laboviana (SL) e da SH, mostrando que as duas levam em consideração a observação e descrição da heterogeneidade ordenada, e optam pela perspectiva em que o processo de variação é condicionado por fatores estruturais e sociais, ambas reconhecem que toda mudança emerge da variação. Também se baseiam em dados reais de uso. Em contrapartida, enquanto a SL enfrenta o paradoxo do observador, e utiliza-se de dados orais que representa uma comunidade de fala, a SH se utiliza de dados escritos, muitas vezes limitados e parciais. Esse fato pode impossibilitar o acesso ao vernáculo da época, tais documentos não permitem generalização, pois não há a possibilidade de estratificação. Na SL se identifica mudança em curso, a que pode vir ou não a acontecer, já na SH a mudança é presente, pois se olha para o passado tentando entender como se deu a mudança.

Lopes cita o trabalho de Bergs (2005) para afirmar que a SH é uma disciplina autônoma que diverge tanto da Linguística Histórica quanto da Sociolinguística atual. Aponta alguns caminhos e desafios para os estudos em SH, como por exemplo, buscar por produções espontâneas, como cartas, diários, peças teatrais, entre outros, é um caminho fundamental, assim como também, controlar as tradições discursivas ou gêneros utilizados, investigar o estilo individual do autor, reconstruir o contexto social, e usar ferramentas computacionais da linguística de corpus. Lopes atualmente 


\section{REVISTA DA ABRALIN}

utiliza as cartas como objeto de estudo, e destaca seus aspectos positivos que facilitam a pesquisa, mas também suas limitações. Utiliza-se de Romaine (1988) para afirmar a necessidade de propor um conjunto de procedimentos para reconstrução da língua em seu contexto social e usar os achados da Sociolinguística como controle dessa reconstrução. Destaca a impossibilidade de aplicar a metodologia da SL em sua totalidade na SH pela limitação do corpus, e também pelo fato de a língua escrita ter a tendência de ser mais conservadora e representar apenas uma parcela da população que era letrada. Ainda com relação aos documentos utilizados para pesquisa na SH, ressalta que os dados são questionáveis, pelo fato de todas as comunidades serem sujeitas a mistura dialetal, hipercorreção, erros de escrita entre outros problemas. Também relata a facilidade que o pesquisador tem em recuperar a história social do documento quando o autor se trata de um ilustre, no entanto, quando não esse processo pode ficar inviável.

Para concluir sua explanação, Lopes esclarece que a SH foi obrigada a se reinventar para dar conta da natureza que o estudo desenvolve, e do material de análise em que se baseia. É necessário ter o cuidado de procurar os documentos em que possivelmente o fenômeno escolhido para estudo vai aparecer. Considera igualmente importante a observação da disponibilidade de material para $\mathbf{O}$ recorte cronológico estudado, e a qualidade de informação existente sobre os informantes e ou sociedade em que viveram.

Dando continuidade às discussões, Rosane Berlink menciona o livro de Mattos e Silva, no qual afirma a Linguística Histórica ter possibilidade de trabalhar tanto a reconstrução linguística como social do Brasil. Berlink ressalta algumas questões já mencionadas anteriormente por Lopes, como é o caso dos desafios enfrentados pela limitação do corpus de análises. Recorda que em 1980 a Linguística Histórica foi retomada no cenário brasileiro, e as peças teatrais, que são seu objeto de estudo atualmente, na década de 1980 foram muito exploradas como fonte de dados para pesquisa. Como havia a preocupação de buscar textos que retratassem o vernáculo da época estudada, foram privilegiados textos de caráter popular, principalmente a comédia, uma vez que tende a representar a língua oral informal. Do ponto de vista da autora, com a expansão dos estudos do português brasileiro as peças teatrais foram marginalizadas, o que pode ser vestígios da ausência desse gênero textual em determinados períodos da história.

Berlink menciona Coelho e Nunes de Souza (2014) para apontar a possibilidade de ilegitimidade dos estudos em peças teatrais, pela possível intromissão do estilo do autor nos textos, e também a maneira como este observa determinados perfis sociais, tais fatores podem ocasionar uma distorção do vernáculo do período histórico. Para isso, a autora propõe um novo olhar e uma nova maneira de analisar esse tipo de corpus. Trazendo Romaine (1988), afirma que toda fonte, sendo ela literária ou não, pode ser utilizada como corpus. Pontua as principais características das peças teatrais, como também evidencia trabalhos desenvolvidos por um grupo de estudos do qual é coordenadora. Ressalta a necessidade de entender o contexto sócio-histórico as comunidades de fala para uma análise mais aperfeiçoada dos manuscritos. Apresenta a tese de Cyrino (1997), para mostrar as descobertas feitas em peças de teatro, e faz menção a alguns dos seus trabalhos desenvolvidos no mesmo âmbito. Por último, faz algumas reflexões voltadas para os ganhos da $\mathrm{SH}$ em análises de textos dramáticos. 


\section{REVISTA DA ABRALIN}

Finalizando as discussões, Huda Santiago reflete sobre a identificação da inabilidade na escrita em corpora diacrônico. Considerando a impossibilidade de acesso à fala de indivíduos no passado, de acordo com Santiago, os documentos escritos são materiais empíricos para o estudo de sincronias passadas. Entretanto, a conferencista destaca que, "é necessário a identificação de fontes escritas mais transparentes com índices que reflitam certos traços de oralidade [...]. Este é um desafio metodológico para o trabalho com os materiais não-literários reunidos em corpora diacrônicos" (BARBOSA, 2006, p. 765). Para a sistematização desse desafio metodológico para o trabalho de sincronias passadas, Santiago apresenta os itens elencados por Barbosa (2005, p. 28), entretanto, enfatiza que, entre os itens mencionados, sua apresentação será concentrada acerca do enfrentamento deste último desafio, com o objetivo de identificar os redatores inábeis e pouco hábeis.

Discorrendo sobre os aspectos de inabilidade, a professora apresenta os níveis de execução gráfica classificados por Petrucci (1978), sendo o nível elementar de base o interesse de seu trabalho por tratar, entre outros aspectos, sobre a ausência de caracterização estilística da escrita. Entretanto, somente esta proposta não seria suficiente para o estudo realizado, portanto, Santiago soma ao seu estudo o proposto por Marquilhas (2000), a qual propõe a observação da aparência física, constituída pela caligrafia da mão e por particularidades do suporte. A conferencista ressalta que a aparência física do texto pode não corresponder ao seu nível ortográfico, sendo assim, ela indica a análise gráfica dos manuscritos de modo que haja a verificação de um conjunto de propriedades como a representação silábica da fonologia e os fenômenos de mudança fonética e fonológica.

A partir destas reflexões, Santiago busca em seu estudo identificar as marcas de uma inabilidade em escrita alfabética. Deste modo, é considerada a possibilidade de um contínuo em níveis combinados, como: a escriptualidade e a escrita fonética, a pontuação, a repetição de vocábulos e a habilidade motora e segmentação gráfica. A partir da identificação desses aspectos no texto, é possível verificar que não há um único padrão para a inabilidade, portanto, é importante observar a presença dos aspetos de escriptualidade e índices grafofonéticos, sendo necessário cruzar estes dois grupos para que haja um melhor resultado.

Como exemplificação, Santiago apresenta fac-símile de duas cartas, na primeira é possível observar maior grau de inabilidade devido à dificuldade do redator em manter o curso da escrita, podendo ser observado também através da edição a correspondência entre a aparência física e os dados de escriptualidade. Na segunda carta a habilidade aparenta ser maior, porém, ao observarmos a edição, os dados de escrita se afastam da convenção e dos índices grafofonéticos, o que demonstra que, apesar de manifestar habilidade motora, o redator encontra-se em um ponto de inabilidade máxima, no contínuo.

Destarte, a conferencista eleva algumas considerações acerca do que foi mencionado, demonstrando que para a identificação dos aspectos de inabilidade em escrita o cruzamento das dimensões permitiu verificar que não há um único padrão de inabilidade e que a inabilidade máxima pode ser identificada pela maior presença de aspectos referentes à escriptualidade em coocorrência aos índices grafofonéticos. 


\section{REVISTA DA ABRALIN}

Consideramos as discussões da mesa de fundamental importância para os estudos em SH, uma vez que versam sobre os desafios enfrentados pelos pesquisadores, e os caminhos viáveis para possíveis pesquisas, as explanações das três apresentadoras foram essenciais para auxiliar os estudiosos interessados na área.

\section{REFERÊNCIAS}

BARBOSA, Afrânio Gonçalves. Tratamento dos corpora de sincronias passadas da língua portuguesa no Brasil: recortes grafológicos e linguísticos. In. LOBO, Tania. et al. Para a história do português brasileiro. Rio de Janeiro, UFRJ, Pós-graduação em Letras Vernáculas: FAPERJ, 2005. p. 25-43.

BARBOSA, Afrânio Gonçalves. Tratamento dos corpora de sincronias passadas da língua portuguesa no Brasil: recortes grafológicos e linguísticos. In. LOBO, Tania. et al. Para a história do português brasileiro. Salvador: EDUFBA, 2006.

BERGS, A. Social networks and historical sociolinguistics: studies in morphosyntactic variation in the Paston letters (1421-1503). Walter de Gruyter, 2005.

COELHO, Izete Lehmkuhl. NUNES DE SOUZA, Christiane Maria. Uma proposta metodológica para o tratamento da variação estilística em textos escritos. In: GÖRSKI, Edair Maria; COELHO, Izete Lehmkuhl; NUNES DE SOUZA, Christiane Maria (Org.). Variação estilística: Reflexões teórico-metodológicas e propostas de análise. Florianópolis: Insular, 2014. p. 163-199. (Coleção Linguística).

CYRINO, S. O objeto nulo no português brasileiro: um estudo sintático-diacrônico. Londrina: Editora da UEL, 1997.

MARQUILHAS, Rita. A faculdade das letras: leitura e escrita em Portugal no séc. XVII. Lisboa: Imprensa NacionalCasa da Moeda, 2000.

PETRUCCI, Armando. Scrittura, alfabetismo ed educazione grafica nella Roma del primo cinquecento: da um libretto di conti di Maddalena Pizzicarola in Trastevere. Scrittura e Civiltá, Roma, n. 3. p. 163-207, 1978.

ROMAINE, Suzanne. Pidgin and creole languages. New York: Longman, 1988.

SOCIOLINGUÍSTICA Histórica: caminhos e desafios. Mesa-redonda apresentada por Célia Regina dos Santos Lopes, Rosane de Andrade Berlink e Huda da Silva Santiago.[s.l, s.n], 2020. 1 vídeo (1h 49min 20s). Publicado pelo canal da Associação Brasileira de Linguística. Disponível em:

$<$ https://www.youtube.com/watch?v=nE4i53QDacE > Acesso em: 23 jul. 2020. 